\title{
Fuzzy Modelling of the Academic Staff Attestation Process
}

\author{
Milena Lambeva \\ Artillery, Air Defense and CIS Faculty \\ Vasil Levski National Military \\ University \\ Shumen, Bulgaria \\ uzunova_milen@abv.bg
}

\author{
Valentin Atanasov \\ Artillery, Air Defense and CIS Faculty \\ Vasil Levski National Military \\ University \\ Shumen,Bulgaria \\ valopaint@yahoo.com
}

\begin{abstract}
A large class of real-world problems, arising in the administrative - organizational systems is connected with the attestation of the academic staff in accordance with predefined and linguistically described evaluation criteria. Such problems are solved in the circumstances of uncertainties of different types. The process of interpretation goes together with some ambiguity and inaccuracy due to the subjective interpretation of the criteria by experts. The Fuzzy Set theory provides a convenient apparatus for formalization and creation of new intelligent decision-making methods, based on analysis and processing of the expert knowledge. This paper offers a method of fuzzy modelling of the problem of scientific and pedagogical staff attestation which gives the possibility of an adequate interpretation of the attestation results. The method can be implemented programmatically and can be incorporated in the systems of education quality management.
\end{abstract}

Keywords - Artificial intelligence methods, attestation of the academic staff, fuzzy models.

\section{INTRODUCTION}

The attestation of the academic staff is a "procedure of systematic formalized assessment according to the specified criteria for the correspondence of the employee's activity to the standards of work performance at a given workplace, for a given position, for a certain period of time" [1].

Attestation of scientific and pedagogical staff is an important condition for establishment of an academic work climate in scientific communities and it contributes to the achievement of scientific results. The implementation of quality management systems of training requires automation of this process through the development of mathematical methods for an adequate assessment of cadre staff. The development of automated intelligent systems for attestation of the academic staff is an actual problem on which scientists from many universities work $[2]-[6]$.

The use of such systems in practice of educational institutions can significantly facilitate the work of specialists in the field of pedagogical diagnostics and contribute to the objectification of the evaluation process of academic staff and elimination of subjectivity and randomness.

II. Analysis Of The Decision-Making Process For The Estimation Of The Scientific And Pedagogical STAFF

The attestation of the personnel in departments is carried out by the head of the department and is sometimes discussed by the scientific council of the department.

Analysing the process of thinking of the expert (the head) in the decision-making process for evaluation of the scientific and pedagogical staff, we can draw some conclusions related to the essence of this process.

The analysis of the decision-making process for evaluation of scientific and pedagogical staff shows that:

1. Evaluation criteria are fuzzy and are given by the linguistic terms of the type:

- employee always (sometimes, never, often, rarely) takes part in the activities of the department;

- the employee has good (bad, neutral, excellent) relations with the colleagues (students);

- has a lot of (a few, several, no) scientific publications;

- the scientific results are excellent (good, bad, insignificant);

- conducts classes at a high (bad, low, satisfactory) methodological level;

- has excellent (bad, insufficient, good) scientific preparation;

- helps colleagues (students) always (very rarely, it's hard to make them help someone, never helps anyone), etc.

2. The choice of criteria is carried out by experts and strongly depends on their experience, professionalism and competence.

3. In real problems, the criteria are formulated linguistically; the process of interpretation is accompanied by inaccuracy and ambiguity due to the subjective interpretation by experts. 
4. Expertise and ranking of scientific and pedagogical staff is a result of establishing fuzzy relations between evaluations according to the fuzzy criteria and are formulated on linguistic scales.

5. In the process of resources ranking, we want to obtain a scalar quantitative or qualitative assessment on the basis of particular quantitative or qualitative estimates in accordance with pre-determined criteria.

Therefore, the task of attestation of scientific and pedagogical staff belongs to the class of multicriteria, non- formalized problems that are characterized by fuzzy criteria and linguistic scales of assessments.

The decision-making process is subjective, which does not allow the application of well-known classical methods and models of decision-making theory. Therefore, for the formalization and decision-making it is appropriate to use the apparatus of fuzzy sets, which makes it possible to model the uncertainties and to formalize the fuzzy decision-making process by the expert.

\section{Formalization Of The Problem Of The Academic Personel Attestation}

We assume that a linguistic variable (LV) [7] < teacher's work $>$ with a given term-set, for example $\{\mathrm{bad}$, satisfactory, good, excellent $\}$, is subject to assessment. For estimation we use the criteria representing linguistic variables of lower rank, which can be more easily assessed.

Let:

$D$ - discrete or continuous set of diagnoses;

$P-\left\{p_{1}, p_{2}, \ldots p_{m}\right\}-$ a discrete set of teachers which are subject to attestation;

$C-\left\{C_{1}, C_{2}, \ldots C_{n}\right\}$ - a discrete set of evaluation criteria defined by experts;

$A=\left\|a_{i j}\right\|, i=1,2, \ldots m, j=1,2, \ldots n$ - the matrix containing the results of evaluating teachers;

$a_{i j} \in L_{j}$ - an estimation of the $i^{\text {th }}$ teacher in accordance with the $C_{j}$-criterion;

$L_{j}$ - a discrete or continuous scale of estimates in accordance with the $C_{j}$-criterion;

In practice for an estimator, it is easier to use the same scales for the assessment according to different criteria, i.e

for example

$$
L_{1}=L_{2}=\ldots=L_{n}=L
$$

$$
L=\{\text { bad, satisfactory, good, excellent }\}
$$

The greatest meaningful correspondence of the linguistic model of decision-making process for attestation of scientific and pedagogical staff can be achieved if we consider it as a diagnostic problem of the kind:

$$
<P, C, L, A, D>
$$

with the following formulation:

For each teacher $p_{i} \in P$ the diagnosis $d \in D$ must be determined on the basis of the results in the matrix $\mathrm{A}$ containing the estimations in accordance with the criteria
$C$ given in the $L$ scale.

Formally, this means to find an injective image:

$$
\Omega: P \rightarrow D
$$

of the set of teachers subject to attestation to the set of diagnosis $\mathrm{D}$, in which each element $\mathrm{p}_{\mathrm{i}} \in \mathrm{P}$ corresponds to exactly one element $\mathrm{d} \in \mathrm{D}$.

\section{Fuzzy Model Of The Problem Of The Academic Staff Attestation}

The identification of the image $\Omega$ can be obtained on the basis of the analysis of the evaluation criteria and the decision-making process.

Most often in practice, fuzzy criteria of the kind $<\beta$ is $\beta^{*}>$ are used [8], where $\beta$ is the name of the linguistic variable:

$$
(L V)<\beta, \mathrm{T}_{\beta}, \mathrm{X}_{\beta}, G_{\beta}, M_{\beta}>
$$

on the universum $\mathrm{X}_{\beta}, \mathrm{T}_{\beta}$ is the term set, $\beta \in \mathrm{T}_{\beta}, G_{\beta}$ is the set of rules for obtaining new $L P$ values, $M_{\beta}$ is the set of rules for transforming new values into a fuzzy variable [3]. For example, an estimation $\{$ good skills for teamwork\}, which is a fuzzy set on an arbitrary set of teachers, can be modeled by a linguistic variable of the form $\beta, \mathrm{T}_{\beta}, \mathrm{X}_{\beta}, G_{\beta}, M_{\beta}>$, where:

$$
\beta=<\text { teamwork skills }>
$$

$$
\mathrm{T}_{\beta}=\{\text { bad, satisfactory, good, excellent }\}
$$

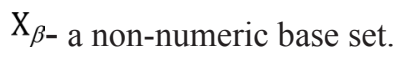

The decision-making process is a fuzzy implication [9] of the form:

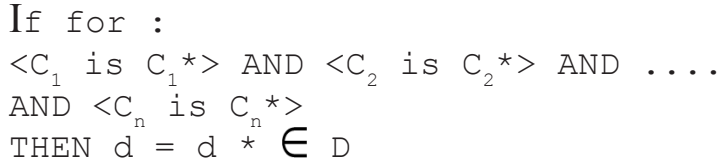

In the process of attestation of teachers, the head of the scientific section actually defines a vector-valued degree of membership to the Cartesian product $C=C_{1} x C_{2}$ $x \ldots \ldots x C_{n}$ of fuzzy criteria with the membership function [9]:

$$
\begin{gathered}
\mu_{c 1 x c 2 x \ldots x c n}\left(p_{i}\right)= \\
\left(\mu_{c 1}\left(p_{i}\right), \mu_{c 2}\left(p_{i}\right), \ldots \mu_{c j}\left(p_{i}\right), \ldots, \mu_{c n}\left(p_{i}\right)\right)=
\end{gathered}
$$$$
\left(l_{i 1}, l_{i 2}, l_{i 3}, \ldots l_{i n}\right) \text {, }
$$

is a multidimensional fuzzy set over the set of attested ones, heterogeneous in the general case when :

$$
\begin{aligned}
& L_{1} \neq L_{2} \neq \ldots \neq L_{n}: \\
& \mu_{c 1 x c 2 \ldots x c n}: P \rightarrow L_{1} \times L_{2} \times \ldots \times L_{n}
\end{aligned}
$$

and homogeneous, provided that $L_{1}=L_{2}=$ $\ldots=L_{n}$ :

$$
\mu_{c 1 x c 2 \ldots x c n}: P \rightarrow=L_{n}
$$


To obtain the diagnosisd $\in D$ for $p_{i} \in P$, we need to transform the evaluation vector into a scalar. This can easily be done by assuming that estimation scales coincide, i.e.

$$
\begin{gathered}
L=L_{1}=L_{2}=\ldots=L_{n}= \\
\left\{l_{1}, l_{2}, \ldots l_{k}\right\} \text { and } D=\left\{d_{1}, d_{2}, \ldots d_{k}\right\}
\end{gathered}
$$

For each element $\left(l_{i l}, l_{i 2}, l_{i 3}, \ldots l_{i n}\right)$ of the set $\mathrm{C}$, we introduce the following norm:

$$
\begin{aligned}
& \quad C \rightarrow[0,1], \quad\left(p_{i}\right)=\left(l_{i 1}, l_{i 2}, l_{i 3}, \ldots l_{i n}\right) \mid= \\
& \frac{\mathrm{i}_{1}+\mathrm{i}_{2}+\ldots+\mathrm{i}_{\mathrm{n}}}{\sum_{\mathrm{i}=1}^{\mathrm{i}=\mathrm{n}} \mathrm{i}}
\end{aligned}
$$

and multivalued function:

$$
\begin{aligned}
& \varphi:[0,1] \rightarrow D, \varphi(x)= \\
& d_{j} \text { for } x \quad\left[\left(\begin{array}{ll}
j & 1) / k, j / k]
\end{array} .\right.\right.
\end{aligned}
$$

The required image $\Omega$, can be represented as a composition $\mu, h, \varphi$ in the following way:

$$
\Omega: P \stackrel{\mu}{\rightarrow} L^{n} \stackrel{\mathrm{h}}{\rightarrow}[0,1] \stackrel{\varphi}{\rightarrow} D
$$

\section{Fuzzy Model Analysis}

In general, the manager can choose an assessment from:

- $\quad$ a linearly ordered set $L=\left\{l_{1}, l_{2}, \ldots l_{k}\right\}$, that meets the requirements of the finiteness and completeness;

- Interval $[0,1]$.

The scales used in practice can be reduced to these two simple transformations. Scales of the form $L=$ $\left\{l_{1}, l_{2}, \ldots l_{k}\right\}$ correspond to a greater extent to the characteristics of human thinking.

It is easier for the manager to assess the work of an employee using a qualitative scale, for example:

$<\mathrm{X}$ is well prepared, has many publications, always helps colleagues, etc. $>$.

In the same way, diagnoses can be chosen from:

- a linearly ordered set $D=\left\{d_{1}, d_{2}, \ldots d_{k}\right\}$;

- the Interval $[0,1]$, showing the intensity of the investigated LV.

In the first case, the staff will be divided into disjoint classes of excellent workers, poor workers, etc. Bearing in mind that there not many people in scientific task groups (7-15), this is quite suitable for the attestation process. The interval $[0,1]$ will provide the possibility to get a quantitative assessment and rank the employees.

\section{Conclusions And Future Work}

The proposed method of fuzzy modelling of academic staff estimation problem makes it possible to adequately interpret the results of attestation.

Practice shows that we think in fuzzy, qualitative categories, so the fuzzy model is more adequate to human thinking than the models of conventional mathematics.

A fuzzy model can be used in practice as, because it allows a software application Fuzzy system for the academic staff attestation is being developed in the National Military University of Bulgaria. This intelligent system for attestation uses the above described method.

\section{REFERENCES}

[1] Борисова Е., “Оценка и аттестация персонала.“, Питер, 2002, ISBN 5-94723-388-6

[2] Saint Petersburg State University, "Two-factor multi-criteria methodology of certification of scientific and pedagogical workers of St. Petersburg state University on the basis of indicators of efficiency of their research and educational activities based on their personal achievements. Report on the research work". Available: https://docviewer.yandex.ru/ view/0/?*=un9UldlP55D4gd6Mye1 Yi5KMeqV7InVybCI6Imh0dHA6Ly9jc3Iuc3BidS5ydS93cC1jb250ZW50L3VwbG9hZHMvMjAxMi8wMy9yZXBvenRfYXR0ZXN0YXRpb24uZG9jIiwidG10bGUiOiJyZXBvenRfYXR0ZXN0YXRpb24uZG9jIiwidWlkIjoiMCIsInl1IjoiOTM4NTg3OTAxMTQ4NjgzMTk0NiIsIm5vaWZyYW11Ijp0cnV1LCJ0cyI6MTQ5MjE1MDUwMDUxNH0\%3D\&lang=ru [Accessed: April 14, 2018]

[3] Vasil Levski National Military University, "Rules for recruitment, development, assessment and certification of academic staff in the National Military University "Vasil Levski"". Available: http://nvu.bg/sites/default/files/nmu_files/norm_baza/ pravilnici_nvu/4-Prav_podb-ocen-razv-atestir-akadem-sastav.pdf [Accessed: April 14, 2018]

[4] Dubois D., Grabisch M., Prade H., Smets P. Assessing the value of a candidate. Comparing belief functions and possibility theories. XVth Conf. Uncertainty in Artificial Intelligence, San Francisco, 1999

[5] Dubois D., Grabisch M., Prade H., Smets P. Using the transferable belief model and a qualitative possibility theory approach on an illustrative example:the assessment of the value of a candidate. Available: http://iridia.ulb.ac.be/ psmets/SelCandiFusion. pdf [Accessed April 14, 2018]

[6] Slavyanov K.O., An algorithm of fuzzy inference system for human resources selection tools, "Society. Integration. Education", Proceedings of the International Scientific Conference. Volume V, Rezekne, May 25th-26th, 2018. 445-454, http://dx.doi. org/10.17770/sie2018vol1.3311

[7] Заде Л. Понятие лингвистической переменной и ее применение к принятию приближенных решений. - М.: Мир, 1976

[8] Нечеткие множества в системах управления. /Под ред. Ю.Н.Золотухина. Курс лекций в Новосибирском Государственном Университете, 2000

[9] Василева М., Размити множества. Теория и практика. ЦВКБТроян, 2008., ISBN 978-954-9681-33-8 